\title{
No primary association between LMP2 polymorphisms and extraspinal manifestations in spondyloarthropathies
}

Thomas Höhler, Thomas Schäper, Peter M Schneider, Frank Krummenauer, Christian Rittner, Karl-H Meyer zum Büschenfelde, Elisabeth Märker-Hermann

\begin{abstract}
Objective-To investigate the potential role of the HLA-linked LMP2 (low molecular weight protein) gene polymorphisms in conjunction with DR4 and DR7 on extraspinal disease manifestations in HLA-B27 positive patients with spondyloarthropathy.

Methods-172 patients with spondyloarthropathy, 46 healthy, HLA-B27 positive blood donors, and 99 unrelated controls were typed for HLA-class I and II antigens. LMP2 alleles were determined by polymerase chain reaction and subsequent restriction enzyme digestion.

Results-There were statistically nonsignificant increases of DR4 and DR7 in spondyloarthropathy subjects. However these differences did not relate to specific extraspinal manifestations. There were no significant differences in the LMP2 genotype distribution in the disease groups. All differences in LMP2 genotype frequencies disappeared when correcting for DR4, which was in linkage disequilibrium with the LMP2B allele.

Conclusions-There is no independent association between LMP2 genotypes and the occurrence of uveitis or peripheral arthritis in HLA-B27 positive subjects with spondyloarthropathy. DR4 and DR7 do not contribute to these disease manifestations.
\end{abstract}

(Ann Rheum Dis 1997;56:741-743)

The seronegative spondyloarthropathies encompass a variety of disorders, which include reactive arthritis, psoriatic arthritis, arthritis associated with inflammatory bowel disease, undifferentiated spondyloarthropathy, a subgroup of juvenile chronic arthritis, and ankylosing spondylitis as a prototype of this group of related disorders. ${ }^{1}$ These disorders are linked together by common clinical, laboratory, and genetic factors. The most prominent genetic factor is the association with HLAB27, which is found in $95 \%$ of patients with ankylosing spondylitis and with lower prevalence in the other spondyloarthropathies. ${ }^{1}$ Linkage of HLA-B27 and ankylosing spondylitis has been comprehensively shown in a large family study, which suggested that the disease is inherited in an autosomal dominant pattern with a low penetrance of $20 \% .^{2}$ It is still unclear, however, whether other genes inside the MHC contribute to the disease risk or influence the risk for extraspinal disease manifestations as peripheral arthritis or uveitis.

Transcomplementation has been shown for HLA-B60, which increases the risk for ankylosing spondylitis more than threefold in B27 positive people. ${ }^{3}$ The contribution of HLA-DR genes to extraspinal disease manifestations is controversial. One group has reported an increase of DR7 in patients with peripheral arthritis $^{4}$ and DR8 seems to predispose to uveitis in Japanese patients. ${ }^{5}$ A number of recent studies has focused on the association of MHC class II encoded TAP (transporter associated with antigen processing) and LMP (low molecular weight protein) genes, which participate in class I antigen processing. ${ }^{6-8}$

The LMP2 gene encodes a subunit of the proteasome, a cytoplasmic catalytic complex involved in the generation of antigenic peptides that are loaded on class I molecules within the endoplasmic reticulum. ${ }^{9}$

The LMP2 gene contains a coding polymorphism causing the exchange of arginine for histidine. ${ }^{6}$ Although nothing is known about the functional consequences of the LMP2 polymorphism, two recent studies reported an association of the LMP2 gene polymorphism with extraspinal disease in HLA-B27 positive subjects with ankylosing spondylitis. ${ }^{67} \mathrm{~A}$ third investigation could not confirm these findings. ${ }^{8}$ Unfortunately all three studies did not investigate the issue of linkage disequilibrium with class II antigens.

This study was done to test the hypothesis of an HLA-DR independent association between LMP2 genotypes and extraspinal manifestations in spondyloarthropathies. We did not find any such association. Deviations in LMP2 genotype frequencies could be explained by 
Table 1 LMP2 genotype distribution in the investigated groups. LMP2BB genotypes were compared against LMP2AB and AA genotypes. The significant differences in genotype distribution were between DR4 positive patients with spondyloarthropathy $(S p A)$ compared with DR4 negative patients with $S p A\left(^{\star}\right)$ and between DR4 positive patients with $S p A$ compared with DR4 negative, B27 controls $(t)(p<0.03)$

\begin{tabular}{|c|c|c|c|c|c|c|}
\hline \multirow[b]{2}{*}{ Subjects } & \multicolumn{2}{|l|}{$A A$} & \multicolumn{2}{|l|}{$A B$} & \multicolumn{2}{|l|}{$B B$} \\
\hline & Number & $\%$ & Number & $\%$ & Number & $\%$ \\
\hline Controls $(\mathrm{n}=99)$ & 8 & 8.1 & 42 & 42.4 & 49 & 49.5 \\
\hline B27 positive controls $(n=46)$ & 3 & 6.5 & 21 & 45.7 & 22 & 47.8 \\
\hline B27 positive controls, DR4 negative $(n=38)$ & 3 & 7.9 & 18 & 47.4 & $17 \dagger$ & $44.4 \dagger$ \\
\hline $\mathrm{SpA}(\mathrm{n}=172)$ & 12 & 7.0 & 64 & 37.2 & 96 & 55.8 \\
\hline Ankylosing spondylitis $(n=141)$ & 9 & 6.4 & 52 & 36.9 & 80 & 56.7 \\
\hline $\mathrm{SpA}$, without peripheral arthritis and uveitis $(\mathrm{n}=79)$ & 6 & 7.6 & 32 & 40.5 & 41 & 51.9 \\
\hline SpA, DR4 negative $(n=119)$ & 10 & 8.4 & 49 & 41.2 & $60^{\star}$ & $50.4^{\star}$ \\
\hline SpA, DR4 positive $(n=53)$ & 2 & 3.8 & 15 & 28.3 & $36^{\star} \dagger$ & $67.9^{\star} \dagger$ \\
\hline $\mathrm{SpA}$ and peripheral arthritis $(\mathrm{n}=72)$ & 5 & 6.9 & 27 & 37.5 & 40 & 55.6 \\
\hline SpA and peripheral arthritis, DR4 negative $(n=52)$ & 5 & 9.6 & 21 & 40.4 & 26 & 50.0 \\
\hline SpA and uveitis $(n=46)$ & 2 & 4.4 & 16 & 34.8 & 28 & 60.9 \\
\hline SpA and uveitis, DR4 negative $(n=30)$ & 2 & 6.7 & 13 & 43.3 & 15 & 50.0 \\
\hline SpA, peripheral arthritis and uveitis $(n=25)$ & 1 & 4.0 & 11 & 44.0 & 13 & 52.0 \\
\hline $\begin{array}{l}\text { SpA, peripheral arthritis and uveitis, DR4 negative } \\
(n=16)\end{array}$ & 1 & 6.3 & 9 & 56.3 & 6 & 37.5 \\
\hline
\end{tabular}

$\star \mathrm{p}=0.04$; odds ratio $2.08 ; 99 \%$ confidence intervals $(0.8,8.15) ; \pi=30 \% . \dagger \mathrm{p}=0.03$; odds ratio $2.62 ; 99 \%$ confidence intervals $(0.78,8.79) ; \pi=27 \%$

differences in HLA-DR frequencies and linkage disequilibrium between DR4 and LMP2B.

\section{Methods}

PATIENTS AND CONTROLS

One hundred and seventy two HLA-B27 positive German white patients with seronegative spondyloarthropathy as defined by the European Spondylarthropathy Study Group preliminary criteria for the classification of spondylarthropathy ${ }^{10}$ were included in this study. Fifty seven subjects $(33 \%)$ were female, 115 subjects $(67 \%)$ were male with a median age of 45.0 years (13-87). The median disease duration was 19.4 years (1-57). Reiter's syndrome was present in two patients, reactive arthritis in seven patients, Crohn's disease in six, and ulcerative colitis in one patient. Fifteen patients with psoriatic spondarthritis had been included in a previous study. All other patients (141 subjects) were suffering from ankylosing spondylitis. Forty seven patients $(27.3 \%)$ had experienced at least one episode of uveitis. Peripheral arthritis had occurred in 74 patients $(43 \%)$ during the disease course.

The control population consisted of 99 unrelated, healthy, German white persons from routine consecutive paternity cases investigated at the Institute of Legal Medicine ${ }^{11}$ and of 46 healthy German white HLA-B27 positive blood donors from Mainz. DNA was prepared from peripheral blood and stored at $4^{\circ} \mathrm{C}$ before use.

TYPING OF CLASS I ANTIGENS

Analysis HLA-B27 was performed on peripheral blood lymphocytes by the standard microlymphocytotoxicity method.

TYPING OF DRB1 GENES

Spondyloarthropathy patients were typed for DRB $1^{\star} 0401-11$ and $\mathrm{DRB} 1{ }^{\star} 0701$, whereas control subjects were typed for $\mathrm{DRB}^{\star} 0101$ DRB1*1601-02. DNA typing was done by nested polymerase chain reaction (PCR) amplification using sequence specific primers as described by Bein et al. ${ }^{12}$
LMP2 GENE POLYMORPHISM

PCR primers and conditions were as described previously. ${ }^{7}$ After PCR amplification samples were digested with HhaI (New England Biolabs) and alleles were assigned after electrophoresis on a $2.5 \%$ agarose gel.

STATISTICAL ANALYSIS

An extensive explorative statistical analysis was performed to detect possible differences in the proportion of LMP2BB versus LMP2AA/AB among several subgroups. Statistical analysis was done using the two sided exact Fisher test. Odds ratio and its $99 \%$ two sided confidence intervals are presented. The confidence levels were raised from the usual $95 \%$ to $99 \%$ because no adjustment for multiple comparisions was performed. The posteriori power $\pi$ was calculated using the Casagrande/Pike/ Smith approximation. ${ }^{13}$

\section{Results}

DR ANTIGENS

For DR4 there was an increase of borderline significance in the spondyloarthropathy group compared with HLA-B27 controls $(32 \% v$ $17.4 \%$; $<0.07)$. DR4 frequencies were similar in all investigated spondyloarthropathy subgroups $(30.6 \%$ in patients with peripheral arthritis and $34.8 \%$ in patients with uveitis). There was a non-significant increase for DR7 in the spondyloarthropathy group compared with B27 controls. A similar difference was observed when comparing DR7 frequencies in spondyloarthropathy patients with and without peripheral arthritis ( $15 \%$ v $25 \%$, respectively; $\mathrm{p}<0.1$ ).

\section{LMP POLYMORPHISMS}

Table 1 shows the data on LMP2 genotype frequencies in the different groups. We found no significant differences in the genotype distribution between healthy B27 controls and the entire spondyloarthropathy group. However, the LMP2BB genotype was enriched in DR4 positive patients with spondyloarthropathy $(67.9 \%)$ compared with B27 positive, DR4 negative controls $(44.4 \% ; \mathrm{p}<0,03$; odds ratio 
2.6) and with DR4 negative patients with spondyloarthropathy $(50.4 \% ; \mathrm{p}<0.04 ;$ odds ratio 0.48 ) suggesting linkage disequilibrium of this allele to LMP2B. The non-significant enrichment of the BB genotype in patients with uveitis $(60.9 \% \quad v 47.8 \%$ in $\mathrm{B} 27$ positive controls) was almost equalised when DR4 positive subjects were removed from both groups $(50.0 \%$ v $44.4 \%$ in B27 positive, DR4 negative controls). To exclude the introduction of a bias by choosing a heterogenous patient group encompasing a variety of disorders we analysed the ankylosing spondylitis patients separately. The LMP2BB genotype frequency in these patients matched almost exactly that in the entire spondyloarthropathy group $(56.7 \%$ in ankylosing spondylitis $v 55.8 \%$ in the spondyloarthropathy group). Neither subjects with peripheral joint involvement nor those with uveitis and peripheral arthritis showed any significant deviation in the LMP2 genotype distribution. LMP2A homozygotes were observed in all groups.

\section{Discussion}

Our study shows that there is no independent association between the occurrence of uveitis and peripheral arthritis and the presence of the LMP2 BB genotype in HLA-B27 postive patients with seronegative spondyloarthropathy. Observed differences in LMP2BB genotypes are easily explained by the differences of DR4 frequencies in the investigated subgroups. After correction for DR4, the frequency of LMP2B homozygotes was similar in all spondyloarthropathy subgroups $(51.9 \%$ in subjects with spondyloarthropathy without peripheral arthritis and uveitis; $50 \%$ in subjects with spondyloarthropathy and peripheral arthritis; $50 \%$ in subjects with spondyloarthropathy and uveitis).

Our investigation explains the controversial results of former studies on the association of LMP2B homozygosity with uveitis and peripheral arthritis in patients with seronegative spondyloarthropathies. None of these studies had controlled for DR genes. As shown in our study differences in the number of DR4 positive subjects can cause significant deviations of the LMP2B allele frequencies in disease subgroups. In this type of study it is particularly important to control for DR4 because more than $32 \%$ of HLA-B27 positive patients were DR4 positive. In contrast with other haplotypes that show a high recombination rate between the TAP1 and TAP2 genes DR4 bearing haplotypes seem to be more conserved. ${ }^{14}$ DR4 haplotypes show a particu- larly strong linkage disequilibrium to the DP genes encompasing the LMP2 gene, which lies telomeric to DP. ${ }^{14}$ This explains the observed linkage disequilibrium between DR4 and the LMP2B allele that has been reported from other studies as well. ${ }^{15}$

There was a non-significant increase in the frequency of DR7 between patients with spondyloarthropathy with peripheral arthritis compared with those without peripheral joint disease. In a much smaller study Aaron et $a l^{4}$ had reported an increase of DR7 in ankylosing spondylitis patients with peripheral joint disease. This association is probably a weak one and needs to be confirmed in a much larger study.

This work contains essential parts of the doctoral thesis of Thomas Schäper. We thank Dr Peter Hasenclever, Karl-AschoffKlinik Bad Kreuznach, for the excellent cooperation and the inclusion of numerous patients into our study.

1 Van der Linden S, Van der Heijde DM. Clinical and epidemiologic aspects of ankylosing spondylitis and spondylarthropathies. Curr Opin Rheumatol 1996;8:269-74

2 Rubin LA, Amos CI, Wade JA, Martin JR, Bale SJ, Little $\mathrm{AH}$, et al. Investigating the genetic basis for ankylosing spondylitis. Linkage study with the major histocompatibility complex region. Arthritis Rheum 1994;36:1212-20.

3 Robinson WP, van der Linden SM, Khan MA, Rentsch HU, Cats A, Russell A, et al. HLA-Bw60 increases the susceptibility to ankylosing spondylitis in HLA-B27+ patients. Arthritis Rheum 1989;32:1135-41.

4 Aaron SL, Miller M, Howard J. Complementation with HLA-A and HLA-D locus alleles in ankylosing spondylitis HLA-A and HLA-D locus alleles in ankylosing spondylitis
and peripheral arthritis. J Rheumatol 1985;12:897-904.

5 Monowarul-Islam SM, Numaga J, Fujino Y, Masuda K, Monowarul-Islam SM, Numaga J, Fujino Y, Masuda K,
Ohda H, Hirata R, et al. HLA-DR8 and acute anterior Ohda H, Hirata R, et al. HLA-DR8 and acute anterior
uveitis in ankylosing spondylitis. Arthritis Rheum 1995;38: uveitis in

6 Maksymowych WP, Wessler A, Schmitt-Egenolf M, SuarezAlmazor M, Titzel G, Von Borstel RC, et al. Polymorphism in an HLA linked proteasome gene influences phenotypic expression of disease in HLA-B27 positive individuals. J Rheumatol 1994;21:665-9

7 Maksymowych WP, Suarez-Almazor M, Chou CT, Russell AS. Polymorphism in the LMP2 gene influences susceptibility to extraspinal disease in HLA-B27 positive individuals with ankylosing spondylitis. Ann Rheum Dis 1995;54: 321-4.

8 Burney RO, Pile KD, Gibson K, Calin A, Kennedy LG, Sinnott PJ, et al. Analysis of the MHC class II encoded components of the class I antigen processing pathway in ankylosing spondylitis. Ann Rheum Dis 1994;53:58-60.

9 Bijlmakers MJ, Ploegh HL: Putting together an MHC class I molecule. Curr Opin Immunol 1993;5:21-6.

10 Dougados $M$, van der Linden S, Juhlin R, Huitfeldt B, Amor B, Calin A, et al. The European spondylarthropathy study group preliminary criteria for the classification of spondylarthropathy. Arthritis Rheum 1991;34:1218-27.

11 Höhler T, Weinmann A, Schneider PM, Rittner C, Schopf $\mathrm{RE}$, Knop J, et al. TAP-polymorphisms in juvenile onset psoriasis and psoriatic arthritis. Hum Immunol 1996;51: 49-54.

12 Bein G, Gläser R, Kirchner H: Rapid HLA-DRB1 genotypng by nested PCR amplification. Tissue Antigens 1992;39: 68-73.

13 Casagrande JT, Pike MC, Smith PG. An improved approximation formula for calculating sample sizes for comparing two binomial distributions. Biometrics 1978;34:483-6.

14 Van Endert, Lopez MT, Patel SD, Monaco JJ, McDevitt HO. Genomic polymorphism, and linkage disequilibrium in the major histocompatibility complex encoded antigenin the major histocompatibility complex encoded antigen-

15 Van der Endert PM, Liblau RS, Patel S, Fugger L, Lopez T, Pociot F, et al. Major histocompatibility complex encoded antigen processing gene polymorphism in IDDM. Diabetes 1994;43:110-17. 